\title{
Use of Social Media for Seeking Health Related Information - An Exploratory Study
}

\author{
Navya Bhaskaran, Manish Kumar, Manthan Dilipkumar Janodia* \\ Department of Pharmacy Management, Manipal College of Pharmaceutical Sciences, Manipal University, Manipal 576 104, Karnataka, INDIA.
}

\begin{abstract}
Introduction: Social Media (SM) is evolving and more number of people are experiencing benefits of SM. Though use of social media is beneficial, it has to be carefully calibrated when used for sharing health information. Social networks act as a powerful marketing channels in healthcare industry but many questions need to be resolved. Objective: We carried out a study to understand use of SM to seek health information. Method: The cross sectional study used convenience sampling method. The data was collected with the help of a structured questionnaire and the study was carried out in two different states of India. We received a total of 156 usable responses. Results: Prominently youngsters in the age group of 18-27 years use MS. Majority of the respondents were from health sciences background and had undergraduate qualification. WhatsApp is the preferred SM platform followed by Facebook, YouTube, twitter, blogs and Linkedln. The information searched on SM include disease and related information, and information on medicines. Interestingly, 35 percent of respondents trust health information, 32 percent do not trust the information and 33 percent do not always trust health related information. Respondents stated that health
\end{abstract}

information available through SM should have various controls. Conclusion: In India, at present we do not have legal mechanism to oversee that health information on social media is authentic. Drugs and Cosmetics Act 1940 is archaic and needs transformation including provisions on monitoring and controlling health information available through SM.

Key words: Social Media, Healthcare, India, Regulations.

\section{Correspondence:}

Manthan Dilipkumar Janodia, Department of Pharmacy Management, Manipal College of Pharmaceutical Sciences, Manipal University, Manipal 576104, Karnataka, INDIA.

Phone no: +91820-2922482

Email: manthan.janodia@gmail.com

DOI: 10.5530/jyp.2017.9.52

\section{INTRODUCTION}

Social Media (SM) is evolving and more and more number of people are experiencing benefits of social media. The population using SM is on rise and primarily comprises of youngsters, below 45 year of age. Social media is used in many industries across the world to reach target audience, the customers, by business organizations. In ever changing world and transformation, social media is used for people to people communication. People share their experiences using different forms of social media. Social Media is a broad categorical name for the latest web 2.0 interactive websites and services. ${ }^{1}$ The term social media include social networking sites, collaborative services, blogs, content hosting sites and virtual communities. ${ }^{2}$ The key differentiator of social media vs traditional media is that using social media, users can generate their own content, for example a website, a blogpost, a Facebook page, a twitter account, an interactive portal, WhatsApp chat groups etc. Though use of social media is beneficial, it has to be carefully calibrated when used for sharing health information. Social networks act as a powerful marketing channels in healthcare industry but many questions need to be resolved ${ }^{1}$. Increasing use of smart phones and tablet phones demand for mobile health information has increased manifold. Both smartphones and tablet phones facilitate ease of access to information for a user. ${ }^{2}$ In the $21^{\text {st }}$ century an explosion of information, transmitted as internet based messages, has influenced various aspects of consumer behavior. The consumer behavior that can be influenced include awareness, information acquisition, opinions, attitudes, purchase behavior, and post-purchase communication and evaluation. The promotion related role of social media may be used by consumers to communicate with one another. ${ }^{3}$

Health information remains one of the important topics discussed on internet. ${ }^{4}$ In June 2009, a study by Pew Internet and American Life Project found that 61 per cent of American adults access health care related information online and 41 per cent of them read someone else's commentary or experience about medical and health issues. ${ }^{4}$ A survey in the US identified that about 60 million Americans shared their medical experience with each other; about 72 per cent patients searched online information before or after doctor visit and about 890 hospitals in the US used social media to engage with their patients. ${ }^{5}$ It was expected that by 2015 about 500 million people globally would be using mobile healthcare applications by $2015 .^{5}$

Social Media has left behind old model of one to one communication and transformed it into one to many or many to many. Social Media in healthcare can be considered as "changing the locus of control to patients". ${ }^{6}$ With greater number of patients seeking information about health through use of online sources, and engaging in two way conversations with care providers and other patients, the health care industry has enormous responsibility. ${ }^{7}$ The increased use of social media is not only confined to the United States of America (USA); about 72 per cent of European online consumers are social health users and a study found that adoption of physician only social networks by European doctors doubled in 2012. ${ }^{7}$ It is important to realize that more and more people are accessing health related information via social media. However, due to lack of control and regulations, chances of providing misinformation is high and in many cases it could be fatal.

We carried out the study with the following objectives

(i) to study how widely social media is used as a source of seeking health related information, (ii) identify the age group of population that is most exposed to and influenced by the information available on the social media, 
(iii) to understand the online health information-seeking behaviors of people as to whether they utilize social media and if not, whether they would be willing to use social media to look for health related information.

\section{METHODS}

The study is a cross sectional survey to understand how people use healthcare related information available on social media. Structured and non-disguised questionnaire was used for the study. Questionnaire included open-ended and dichotomous questions. A pilot study was carried out to ensure the questionnaire is usable and conveys the same meaning to respondent as we intended to elicit a response. The other objective of the pilot study was to reveal lacunae and deficiencies in the design of a proposed experiment, so that the deficiencies can be corrected before rolling out the questionnaire to a larger sample. Based on the results of pilot study the, questionnaire was modified and two additional questions were included in the final questionnaire rolled out for study. Non probability convenience sampling method was used. The sample units were people in the age group of 18-45 years. A total of 156 usable responses were received, which were analyzed. The study was carried out for a period of 4 months. Primary data was collected by directly approaching the respondents. Secondary data was collected from various available resources like professional reports, articles etc. The study was carried out at two places which include an educational town in South India, Karnataka and Patna, Bihar. Descriptive statistics was used to analyze the results.

Total number of Questionnaire distributed $(\mathrm{n}=173)$

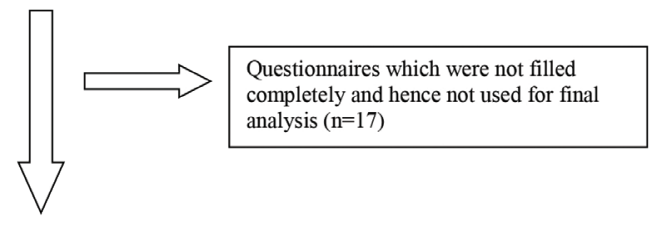

Questionnaires used for Analysis ( $\mathrm{n}=156)$

\section{RESULTS}

The survey had 156 usable responses. The responses were tabulated to identify demographic factors and responses received. The analysis of data including results are discussed below.

Among 156 respondents, 113 respondents were in the age group of 18-27 years. This signified that a major group of the youth is involved in searching for health related information through the use of social media.

The majority of respondents were undergraduates $(113,72.5 \%)$ followed by postgraduates $(39,25 \%)$ and doctorates $(4,2.5 \%)$.

As evident from Figure 3, a large number of respondents belonged to urban areas.

This cross sectional study consisted primarily of respondents from the fields of health science as 78 (50\%) respondents belonged to health sciences background, followed by 51 (33\%) respondents in the field of technology. The study also comprised of a smaller proportion of respondents in the field of management, which were 23 (15\%) and others respondents were who served as military officials and in product design (4\%).

It was identified that people irrespective of their professions involved in searching health realted information via social networks.
Respondents were further asked to rate the social media based on their preferences. The results are shown in Figure 6 below.

The respondents were asked to rank various social networking sites like Facebook, Twitter, YouTube, Blogs, Whatsapp and Linkedin as per their preference of usage.

It is interesting to note that 54 respondents' first preferred SM platform is whatsapp, followed by facebook which was preferred by 40 respondents. Youtube is mentioned as third preferred mode of social media usage by 37 respondents followed by twitter, ranked foruth preference, preferred by 30 respondents. 15 respondents chose blogs, which was ranked fifth preference and 33 respondents opted for LinkedIn as their last preference and ranked it $6^{\text {th }}$.

Respondents were asked how likely they are to trust information available on social media. The results are shown in Figure 8. This proves that people do not blindly trust the information that is being shared unless it has been proven or there are established evidences.

A vast majority of the respondents (71\%) stated that they discuss the information, which they come across on social media, with their healthcare providers whereas the remaning respondents (29\%) did not discuss information accessed throgh social media with their health care providers. This is shown in Figure 9.

As shown in Figure 10, when respondents were asked about their knowledge on presence of multinational pharmaceutical companies' (MNC) presence on social media, 105 respondents (67\%) stated that they were aware of MNCs presence on social media, whereas 51 respondents (33\%) were not aware. This shows that MNCs pharmaceutical companies are visible on social media.

We further probed respondents regarding their support on use of social media to access health related information in India. As it is evidednt from Figure 11, 60 (38\%) respondents were in support of permitting use of social media for health information and almost equal number of respondents, 56 (36\%), stated that social media should be used with close controls for seeking health related information, whereas 40 (26\%) respondents were not in favour of permitting use of social media for health information in India.

\section{DISCUSSION}

The examples of pharmaceutical companies using social media in the US are many. ${ }^{8}$ In a survey it was found that pharmaceutical industry is lagging behind other industries in use of social media ${ }^{9}$ due to tight regulations. The medium has inherent ability enabling pharmaceutical companies to hear differing points of views and ideas, build relationships and sustain deeper, more personal connections but uncontrolled use and nature of conversations poses regulatory challenges. ${ }^{10} \mathrm{~A}$ study conducted in $2010^{11}$ recommends use of social media in improving medical adherence, encourage patients to engage more in their health choices. 60 per cent of Americans use internet while seeking health related information. ${ }^{12}$ Critics have warned of dangers of using social media for health that could lead to adverse effects or even deaths. ${ }^{13}$ In a study by Epsilon, it was found that about 40 per cent of respondents engage with social media on health sites through as they felt that social media will empower them. ${ }^{14}$ Social Media empowers patients to exchange information about self and their health management. ${ }^{15}$ Emotional support received through social media is one of the reasons patients are turning to its use. Physicians through use of social media can share experiences, medical gray areas and updates in their field. ${ }^{16}$ In order to provide support to pharmaceutical marketing firms, the USFDA proposed draft guidance titled "Fulfilling Regulatory Requirements for Post marketing Submissions of Interactive Promotional Media for Prescription Human and Animal Drugs and Biologics" in January 2014. The interactive promotional 
media shall be interpreted as modern tool and technology that often allow for real time communications and interactions (e.g., blogs, microblogs, social networking sites, online communities, and live podcasts that firms use to promote their drugs).$^{17}$ Pharmaceutical industry has responded to the draft guidance by providing several comments on the issue. ${ }^{18}$ Additionally, Bupa Health Pulse Survey 2010 revealed that people searching about health information online are in emerging economies such as India, Brazil, Russia, China and Mexico. In India about $39 \%$ of people surveyed look for health information on internet. ${ }^{19}$ Social media is not devoid of ill effects as identified by Parsuraman. ${ }^{20}$ Direct to Consumer Advertising (DTCA) through social media may lead to use of unwanted medical therapies. ${ }^{21}$ With the large number of advantages, there are a few limitations when social media is considered as a tool for seeking health information since it revolutionized communication over the last two decades. ${ }^{22}$

The existing laws in India, for instance, The Drugs and Magic Remedies (Objectionable Advertisements) Act, 1954 prohibits advertisements for products and services claiming to cure certain medical conditions. The enforcement of the Act by is poor because one finds a number of advertisements in the print media. Further, the Act does not mention advertisements carried out through social media.

In our study we found that most of the respondents were in the age group of 18-37 years (Figure 1), had undergraduate degree (Figure 2), lived in urban places (Figure 3) and belonged to health sciences background, followed by Technology and Management (Figure 4). It can safely be assumed that a large number of youngsters browse through social media for seeking health related information.

It was interesting to note that all the respondents who participated in the study used social media for networking and communication and also seek health related information from various social media depending on their requirements or came across a discussion with regards to health and wellbeing. This is shown in Table 1 . When the respondents were asked as to how often they used SM, it was estimated that majority of them used it on a daily basis. A few responded stating they use SM for health information alternately, once a week or once a month. This is shown in Figure 5. It was observed that out of the 156 respondents most of the respondents relied on Whatsapp for their regular social networking purposes (Figure 6). When respondents were asked what type of health related information they access through social media, it was found that most of them look for diseases and related information (57 respondents), 45 respondents look for information on medicines. In addition, 45 respondents stated that they look for both disease and related information as well as information regarding medicines. 4 respondents stated that they look for other information but did not specify what type of health related information is accessed by them. Rest of the respondents do not access health related information through SM. The results are shown in Figure 7. Respondents who do not access health information through social media stated that they access health information from doctors, nurses, pharmacists, friends, relatives and colleagues. As shown in Figure 8, about 55 (35\%) of respondents stated that they are likely to trust information available on social media, whereas 50 (32\%) respondent stated that they do not trust information available through social media. $51(33 \%)$ respondents stated that they do not always trust social media. Many respondents discuss the information available on SM with their healthcare providers, which is shown in Figure 9. This is a healthy sign as it encourages discussion between the healthcare provider and the patient. MNC pharma companies use SM effectively, especially in developed countries. In order to assess awareness of the respondents we asked them about presence of MNC pharma companies on SM. Majority of respondents were aware of MNC pharma companies' presence on SM. This is shown in Figure 10. In India, the advertisements

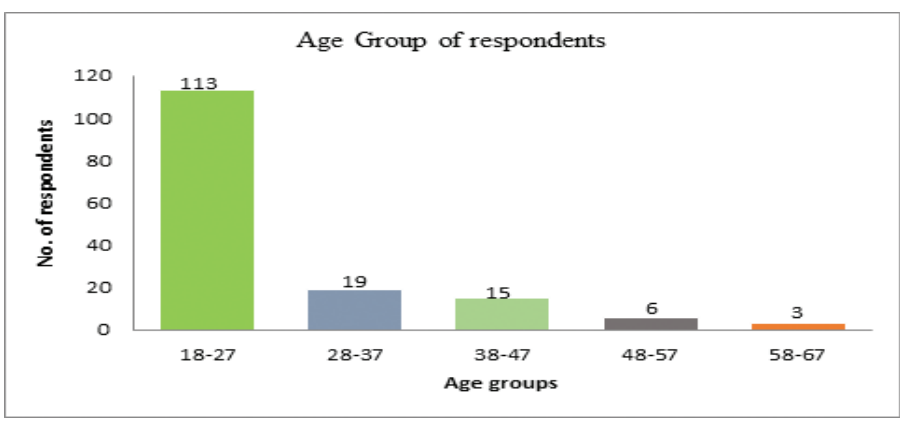

Figure 1: Age group of the respondents.

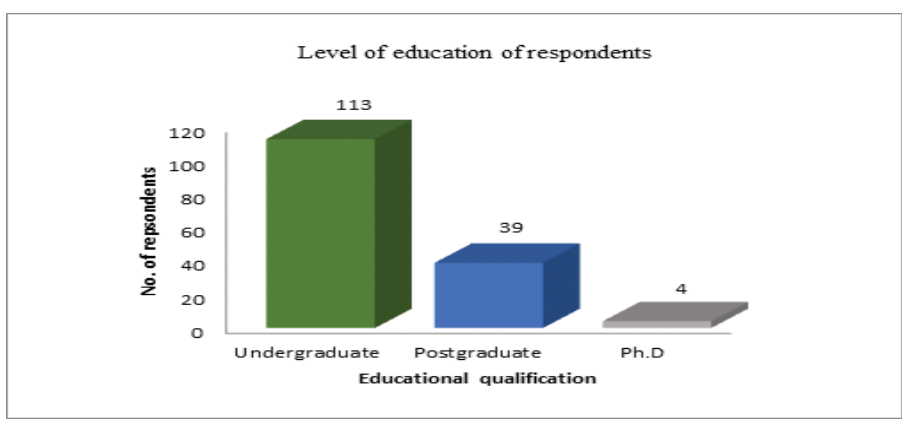

Figure 2: Education level of the respondents.

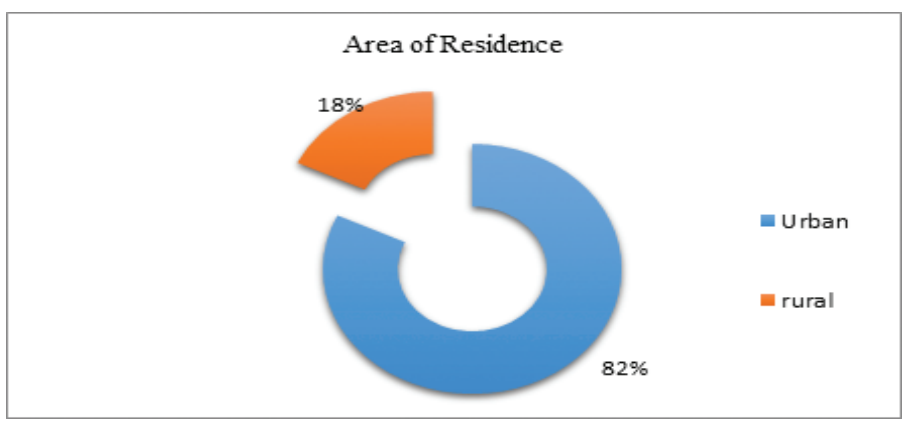

Figure 3: Area of residence.

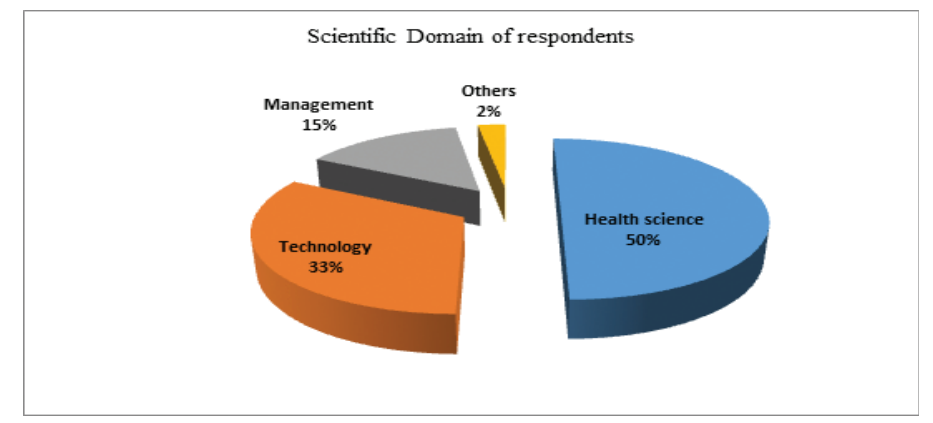

Figure 4: Scientific Domains of the respondents.

regarding medicines are controlled by Drugs and Magic Remedies (Objectionable Advertisements) Act 1954, according to which prescriptions drugs are not permitted to be advertised through mass media. The Act, which was promulgated in 1954 is archaic and since then many developments in the field of pharmaceuticals and advertising have happened. With changing times, it is important to change the Act. The Drugs and Magic Remedies (Objectionable Advertisements) Act 1954 


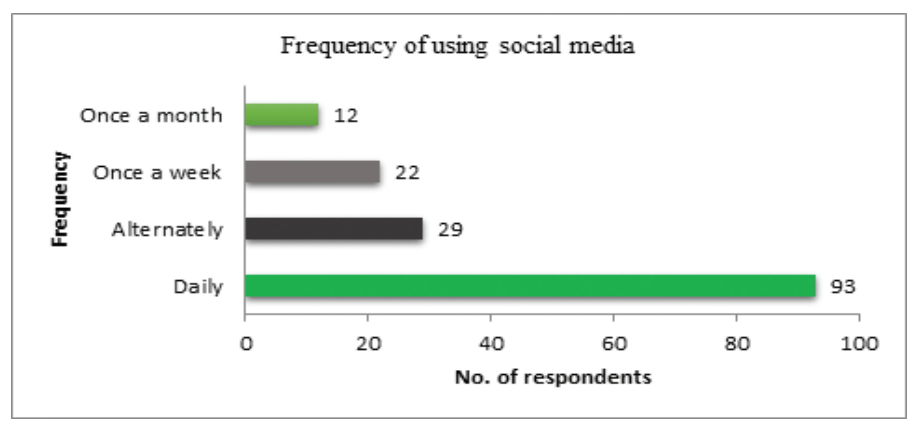

Figure 5: Frequency of using social media.

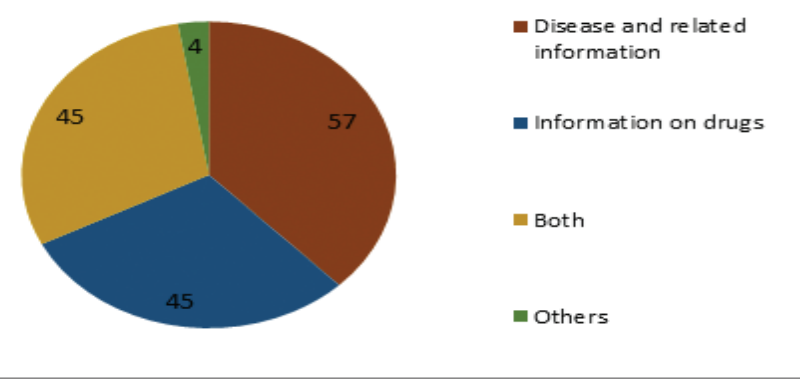

Figure 7: Type of information accessed on social media.

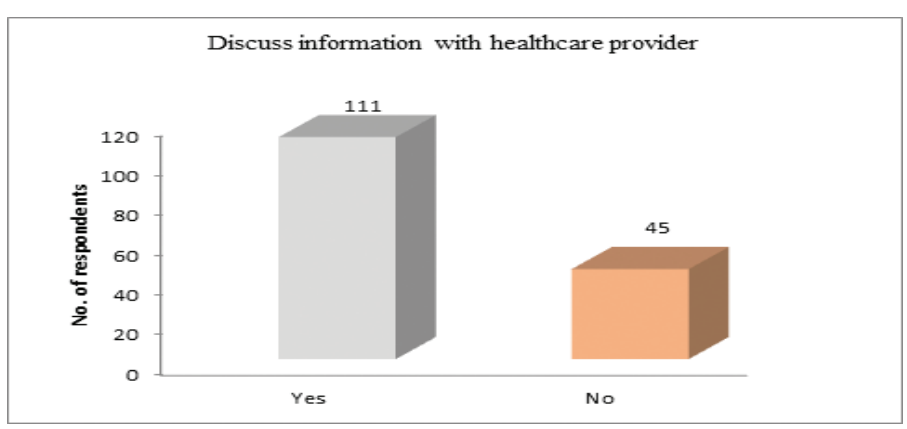

Figure 9: Discuss information with healthcare provider.

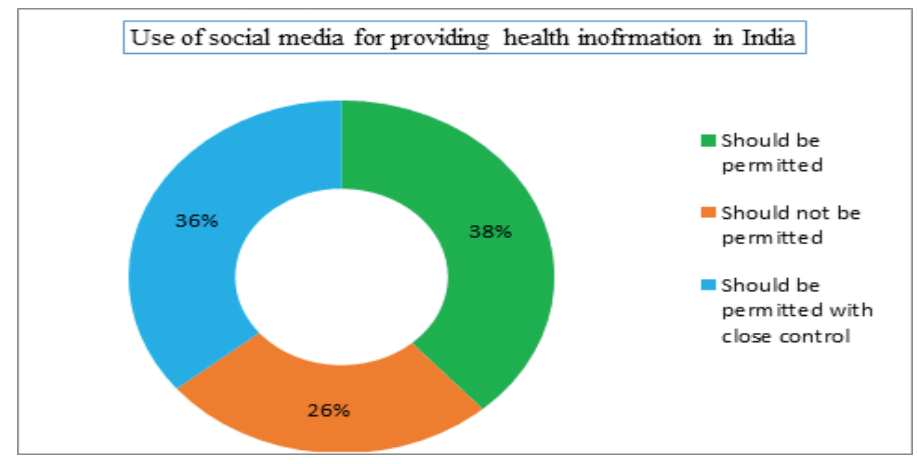

Figure 11: Opinion on use of social media for seeking health related information in India.

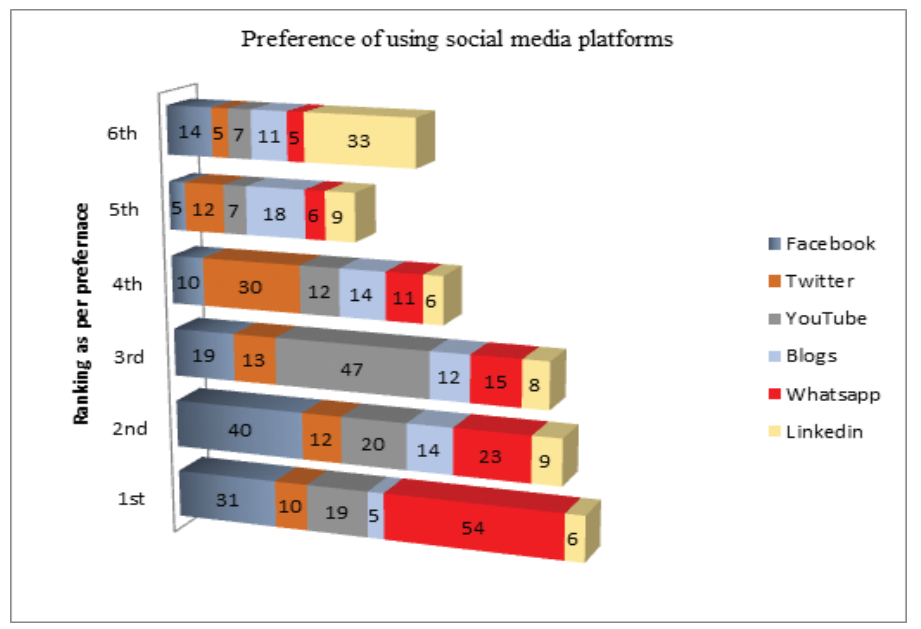

Figure 6: Preference of using social media platforms.

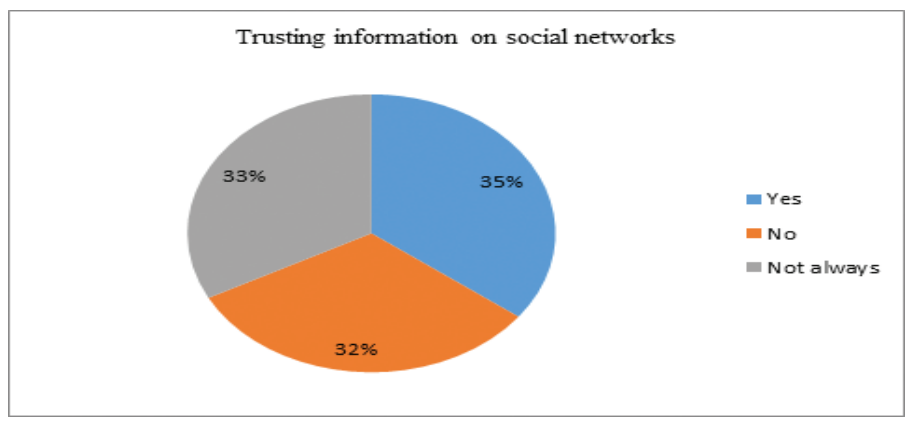

Figure 8: Likelihood of trusting information on social media.

Multinational pharmaceuticals using social networks
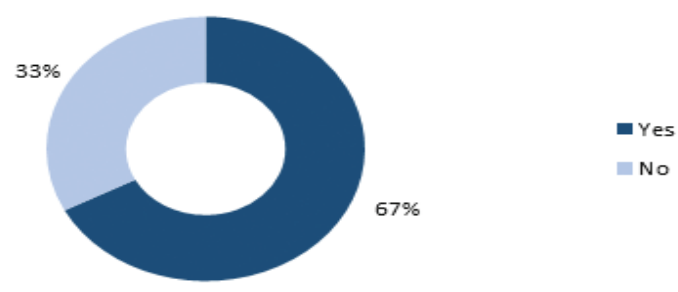

No

Figure 10: Awareness about MNC Pharmaceutical companies' presence on social media.

Table 1: Total number of respondents using social media

\begin{tabular}{cc}
\hline Response & No. of respondents \\
\hline Yes & 156 \\
No & 0 \\
\hline
\end{tabular}


shall include information on use of SM for promoting medicines by pharmaceutical companies in India. In absence of such clarity, it might be possible that the rules are circumvented and SM may be used for promoting medicines, which could be harmful if not properly scrutinized for the authenticity of the information. As shown in Figure 11, respondents are in favour of using SM for use of SM for providing health related information in India. However, there needs to be control and monitoring of such promotional activity. At present we do not have legal mechanism to oversee that health information on social media is controlled. Drugs and Cosmetics Act 1940 is archaic and needs transformation including provisions on monitoring and controlling health information available through SM.

This study had several limitations. First, the study was carried out on a limited sample size of 156 respondents. Second, this was a cross-sectional study involving convenience sampling method. Third, the study was extended to only two states of India-Karnataka and Bihar. Also, the areas where the study was carried out were having socioeconomic disparity with urban-rural divide. Fourth, while collecting and analyzing data, interviewer bias may have crept in.

\section{CONCLUSION}

Out of a total of 156 respondents, 113 respondents belonged to the age group of 18-27. This signified that a major group of the youth is involved in searching health related information via various internet tools available. All the respondents who participated in the study used social media for networking and communication and also seek health related information from various social media depending on their requirements. WhatsApp is the most frequently used mode of networking followed by Facebook, YouTube, twitter, blogs and LinkedIn. The information which is searched on social media include disease and related information, and information on medicines. Interestingly, 35 percent of respondents trust health information available on social media, 32 do not trust the information and 33 percent does not always trust health related information on social media. Where some respondents were not in favour of using SM for health information, majority supported use of SM for health information in India whereas equal number of respondents preferred use of social media for health information with controls. Social media is becoming a new dimension of healthcare. With the advent of technology, enforcement of regulations the quality and reliability of information must be monitored.

\section{ACKNOWLEDGEMENT}

We thank Indian Council for Social Science Research (ICSSR) for providing Research Grant titled "Use of social media for seeking health related information: A survey to understand policy perspective" awarded to Manthan D Janodia, Associate Professor, Department of Pharmacy Management, Manipal College of Pharmaceutical Sciences, Manipal University, Manipal 576 104, Karnataka, India to carry out further research on the topic.

\section{CONFLICT OF INTEREST}

No conflict of interest are declared.

\section{ABBREVIATION USED}

SM: Social Media; MNC: Multinational Companies; DTCA: Direct to Consumer Advertisement.

\section{REFERENCES}

1. Pharma 2.0: heading toward social media marketing. Whitepaper by Agent D.com Marketing Strategy Consulting. 2011.

2. Engaging patients through social media: Is healthcare ready for empowered and digitally demanding patients? IMS Institute for Healthcare Informatics. January 2014.

3. MangoldWG, Faulds DJ. Social media: The new hybrid element of the promotion mix. Business Horizons. 2009;52:357-65.

4. Social media in the pharmaceutical industry. AstraZeneca White Paper.

5. Transforming Healthcare through Social Media. Impact of Social Media in Healthcare. Wipro.com. Bangalore. 2010

6. Hawn C. Take Two Aspirin And Tweet Me In The Morning: How Twitter, Facebook, And Other Social Media Are Reshaping Health Care. Health Aff. 2009;28(2):361-8.

7. Digital Health: Building Social Confidence in Pharma. Weber Shandwick. 2013.

8. Laurent O. Pharmaceutical Companies Are Not Yet a Meaningful Part of the Conversation! Should They Be? Coligane Group.

9. Benchmarking data reveals pharmaceutical industry not connecting social media data with marketing strategies. IBM Institute for Business Value. New York. January 2012.

10. Itskhoki A. Social Media Influence: Foundational Learning for Pharmaceutical Firms. DTC Perspectives. December 2011.1-3.

11. Alkhateeb FM, Clauson KA, Latif DA. Pharmacist use of social media. Int J Pharm Pract. 2011;19:140-2.

12. Greene JA, Kesselheim AS. Pharmaceutical Marketing and the new social media. NEJM. 2010;363(22):2087-9.

13. Sarasohn-Kahn J. The Wisdom of Patients: Healthcare meets Online Social Media. 2008. California HealthCare Foundation.

14. A Prescription for Customer Engagement: An Inside look at social media and the pharmaceutical industry. April 2010. Epsilon. Texas, USA.

15. Social Media: Humanizing the Brand Engaging and Educating. Pharmaceutical Executive, Special report written in association with SAS.

16. Bhatt C, Quigley D. Healthcare and Social Media: A winning formula. Pharma Voice. 2012.58-59.

17. Fulfilling Regulatory Requirements for Postmarketing Submissions of Interactive Promotional Media for Prescription Human and Animal Drugs and Biologics. Draft Guidance. Center for Drug Evaluation and Research (CDER), United States Food and Drug Administration (USFDA). January 2014.

18. Mack J. Pharma Finds Little to Like in Recent FDA Social Media Guidance. Pharma Marketing News. 2014;13(4).

19. McDaid D, Park A-La. Bupa Health Pulse 2010. Online Health: Untangling Web. 2011.

20. Parsuraman S. Human in Wi-Fi zone!. J Young Pharm. 2014;6(4):1-2

21. Ghia C, Jha R, Rambhad G. Assessment of the impact of pharmaceutical advertisements on patient's drug consuming behavior: A questionnaire based survey. J Young Pharm. 2014; 6(2): 58-63.

22. Dhatt KS, Chandrasekaran K. Incorporation of web-based applications and online resources in undergraduate medical education in the Irish Republic. Can new changes be incorporated in the current medical curriculum? J Nat Sci Biol Med. 2014;5(2):445-9 